\title{
Canadian federal penitentiaries as obesogenic environments: a retrospective cohort study
}

\author{
Claire Johnson RD, Jean-Philippe Chaput PhD, Maikol Diasparra PhD, Catherine Richard RD, \\ Lise Dubois $\mathrm{PhD}$
}

Abstract

Background: Very little is known about how incarceration influences a person's weight in Canada. We sought to determine how inmates' weights change during their incarceration in Canadian federal penitentiaries.

Methods: We performed a retrospective, longitudinal cohort study to examine weight change in Canadian federal penitentiaries. To participate, inmates had to have been incarcerated for at least 6 months at the time of the study. Current anthropometric data were measured or taken from medical records, then compared with anthropometric data from the beginning of incarceration (mean followup of $5.0 \pm 8.3 \mathrm{yr}$ ). We examined 3 outcomes: change in weight $(\mathrm{kg})$, change in body mass index (BMI) and rate of weight change $(\mathrm{kg} / \mathrm{yr})$ during incarceration.

Results: A total of 1420 inmates participated in this study. Almost three-quarters $(73.0 \%, n=1037))$ of participants gained weight during incarceration. Inmates gained a median of 6.2 (95\% confidence interval [Cl] 5.6-6.9) kg, and $\mathrm{BMl}$ increased by 2.0 (95\% Cl 1.8-2.2). Obesity rates increased by $71 \%$, from $26.6 \%$ of participants $(n=378)$ on admission to $45.4 \%$ of participants at follow-up $(n=645)$. The proportion of inmates with a BMI in the normal range $(18.5-24.9)$ decreased by $52 \%$. Weight gain was found to be associated with older age, region (Ontario v. Atlantic), ethnicity (Aboriginal inmates showed the highest weight gain), longer incarceration, and longer total sentence. However, weight gain was not associated with sex, feeding system or spoken language.

Interpretation: The Canadian correctional environment can be considered obesogenic, with most inmates experiencing undesirable and rapid weight gain during their incarceration. Rates of obesity increased dramatically during incarceration, and could put inmates at increased risk of obesity-related health problems.

\begin{abstract}
- $t$ is well-established that obesity increases the risk of developing noncommunicable diseases such as type 2 diabetes mellitus, cardiovascular disease and certain types of cancer, as well as all-cause mortality. ${ }^{1}$ Marginalized groups, such as inmates, carry a disproportionately high burden of obesity, because they are often from vulnerable segments of the population with low socioeconomic status. ${ }^{2-4}$ In 2015, a Canadian study found that $64.5 \%$ of inmates were overweight or obese at the beginning of their sentence. ${ }^{5}$ This prevalence is higher than $61.3 \%$ for the general Canadian adult population, as measured by the Canadian Community Health Survey in 2015. ${ }^{6}$ Research done in other countries has identified correctional institutions as obesogenic environments, with most inmates gaining weight during incarceration. ${ }^{7}$ However, very little is known on weight changes among Canadian inmates. This is an important knowledge gap, because there are more than 40000 adults in custody across Canada. ${ }^{8}$ Many correctional physicians anecdotally report weight gain as a substantial problem for inmates, but lack the data to support these claims. ${ }^{9}$ Physicians across Canada are called upon to care for this unique population, because inmates get transferred to community hospitals when their medical condition warrants
\end{abstract}

it. In the event that an inmate gains weight excessively while incarcerated, the burden of care and associated costs will be increased and assumed by Correctional Service Canada. Once released, after less than 5 years for most inmates, ${ }^{10}$ the care and associated costs are covered through provincial health care budgets. ${ }^{11}$

Obesogenic environments are defined as "the sum of influences that the surroundings, opportunities or conditions of life have on promoting obesity in individuals or populations." ${ }^{22,13}$ There is increasing recognition that the environment plays an important role in shaping health behaviours, such as eating habits and physical activities. ${ }^{14}$ For inmates,

Competing interests: Claire Johnson currently works as coordinator of the Nutrition Management Program for Correctional Service Canada. The data and their interpretation are fully represented in the paper, and no censorship has occurred.

This article has been peer reviewed.

Correspondence to: Claire Johnson, cjohn127@uottawa.ca

CMAJ Open 2018. DOI:10.9778/cmajo.20180044 
everything about the prison environment is controlled, including their opportunities to eat and to exercise. ${ }^{4}$ The prison food environment is more controlled than most food environments because inmates eat from the same food service within the penitentiary. In many cases, the kitchen provides a standardized menu to all inmates. The controlled nature of prison provides a unique opportunity to examine weight changes in a homogeneous environment.

The objective of this study was to examine how incarceration influences inmates' weight in Canadian correctional institutions. We hypothesized that inmates would gain weight during incarceration in federal penitentiaries.

\section{Methods}

\section{Study design and study population}

We performed a retrospective, longitudinal cohort study to investigate whether correctional institutions are obesogenic environments. In 2016 and 2017, we collected data from 1420 inmates who volunteered and who had been incarcerated, for at least 6 months, in institutions in Atlantic Canada and Ontario. We used a convenience sample and offered information sessions with the inmate committee in each of the institutions where we were collecting data to encourage volunteers. In addition, we advertised the study on the prisons' telecommunication services. Inmates were asked to submit their names to a designated staff member in each penitentiary.

We initially drew a random list of inmates who we called down to the office to ask whether they wanted to participate. We had a very low response rate with this approach, because inmates found it stressful to be called to the office without knowing why. Most of the inmates contacted in this way refused to participate. We were more successful when we asked for volunteers. In addition, asking inmates to submit their names to a staff member increased their confidence in the study. We did not keep track of who volunteered and who did not. For ethical reasons, we could not gather data on inmates who did not volunteer to participate because we did not have their consent to access their administrative files. We collected data from $88 \%$ of the eligible inmates. Participants were recruited from 5 federal penitentiaries (4 male institutions and 1 female institution) near Kingston, ${ }^{15}$ chosen for reasons of geographical feasibility, and from all 5 federal penitentiaries (4 male institutions and 1 female institution) in New Brunswick and Nova Scotia. ${ }^{15}$ We excluded provincial institutions from our data collection because they are part of a different governance system and only house inmates for shortterm sentences $(<2 \mathrm{yr})$. Inmates with critical illnesses who were admitted to the prison hospital and inmates who were pregnant were excluded from the study.

We used a standardized protocol to collect anthropometric measurements at follow-up for half of our data. The protocol was performed by trained research assistants as part of a faceto-face interview and was guided by a report from the World Health Organization. ${ }^{16}$ Participants' heights were measured while they were standing against a wall, and weights were measured on a scale. Two measurements were taken; a third was taken if the first 2 measurements showed a significant difference ( $\geq 0.5 \mathrm{~cm}$ for height and $>0.5 \mathrm{~kg}$ for weight). The final recorded measurement was the mean of the 2 nearest values. ${ }^{16}$ The rest of the anthropometric measurements (at follow-up and at admission) were objectively measured by a health care professional (i.e., a nurse or dietitian) using a similar protocol. Historical data, such as weight and height on admission to the penitentiary, were drawn from participants' electronic medical records. Sociodemographic data (i.e., sex, age, region, language, ethnicity), information about the institution (i.e., feeding system, security level) and details of the inmates' sentences (i.e., length of incarceration, length of total sentence) were drawn from the electronic Offender Management System.

The 3 main outcomes of the study were change in weight (difference between weight at admission and at follow-up), change in body mass index (BMI; difference between BMI at admission and at follow-up), and annual change in weight during incarceration $(\mathrm{kg} / \mathrm{yr}$; weight change during incarceration divided by the number of years of incarceration at the time of study). In addition, data on weight and BMI were compared with similar data from Statistics Canada's Canadian Community Health Survey of the general Canadian adult population in $2015^{6}$ to contextualize our findings.

\section{Statistical analysis}

We performed $\chi^{2}$ and nonparametric median comparison tests (Wilcoxon and Kruskal-Wallis) to detect significant changes in anthropometric data. We used these tests because the data did not have a normal distribution. Statistical analyses were performed using SAS version 9.4, with significance set at $p<0.05$ for all analyses.

\section{Ethics approval}

Our study was approved by the Research Ethics Board at the University of Ottawa and the research branch at Correctional Service Canada. Inmates volunteered to participate and provided their consent. Because many inmates hesitate to sign documents or forms owing to low literacy or fear of reprisal, participants were able to provide verbal consent if they so preferred. ${ }^{17}$ All personal data collected were coded to ensure confidentiality.

\section{Results}

Table 1 describes our participants, and Table 2 presents the proportion of inmates in each BMI category at admission and at follow-up. On admission to the penitentiary, the combined prevalence of overweight (39.4\%) and obesity (26.6\%) was $66.0 \%$. During incarceration, the combined prevalence of overweight (38.8\%) and obesity (45.4\%) increased to $84.2 \%$ (a $27.6 \%$ increase from admission). The increase in prevalence was mainly due to the $71 \%$ increase in inmates who became obese (BMI $\geq 30.0)$ during incarceration $(26.6 \%$ obesity on admission v. $45.4 \%$ obesity at the time of study). The proportion of inmates with a normal weight (BMI 18.5-24.9) was reduced by about one-half, whereas the proportion of 
inmates who were overweight (BMI 25.0-29.9) remained stable.

Table 3 presents data on median weight change, median BMI change, and median annual weight change by sociodemographic factors. The changes are based on the time elapsed between admission and follow-up (mean duration 5.0 $\pm 8.3 \mathrm{yr}$ ). Overall, inmates gained a median of $6.2 \mathrm{~kg}$. The median BMI increase was 2.0. The annual rate of weight gain was $1.5 \mathrm{~kg}$ per year. No significant differences were seen between men and women, or between Francophones and Anglophones. Inmates between 45 and 64 years of age gained more weight (median $7.6 \mathrm{~kg}$ ) than inmates in other age groups. However, younger inmates, between 18 and 24 years of age, gained weight more rapidly (median $3.5 \mathrm{~kg} / \mathrm{yr}$ ). Regional differences were seen; in Atlantic institutions, although inmates had higher mean BMI on admission compared with those from Ontario (28.2 v. 27.3), they gained less weight (median 5.1 v. $7.1 \mathrm{~kg}$ ) once incarcerated. Aboriginal inmates were more likely to gain weight (median $7.7 \mathrm{~kg}$ ) than inmates of other ethnicities.

Table 4 presents data on median weight change, median BMI change and median annual weight change by institutional factors, such as feeding system, length of incarceration, security level and total duration of sentence. Inmates in medium security institutions had a significantly higher increase in weight (median $7.0 \mathrm{~kg}$ ) than those in minimum or maximum (median $5.6 \mathrm{~kg}$ for both) security penitentiaries. However, this difference was not related to the feeding system. Inmates incarcerated for shorter periods (< $18 \mathrm{mo})$ underwent more rapid weight gain $(6.4 \mathrm{~kg} / \mathrm{yr})$ compared with inmates incarcerated for more than 5 years $(0.64 \mathrm{~kg} / \mathrm{yr})$. Inmates with longer sentences ( $>25 \mathrm{yr}$ ) tended to gain more weight (median $7.7 \mathrm{~kg}$ ) than inmates with shorter sentences.

The combined prevalence for overweight (34.6\%) and obesity $(26.7 \%)$ for the general Canadian population was $61.3 \%$ in 2015 (Appendix 1, available at www.cmajopen.ca/ content/6/3/E347/suppl/DC1). ${ }^{6}$ For inmates, the combined prevalence for overweight (39.4\%) and obesity (26.6\%) was $66.0 \%$ on admission to the penitentiary. This discrepancy is due to the higher rates of overweight in inmates on admission. However, during incarceration, the proportion of inmates with obesity became much higher than that seen in the general population (Appendix 1).

\section{Interpretation}

Almost three-quarters (73\%) of the 1420 participants in our study gained weight during their incarceration. Median weight gain was $6.2 \mathrm{~kg}$, with a median annual weight gain of $1.5 \mathrm{~kg}$ per year. In addition, we saw a $71 \%$ increase in the proportion of inmates with obesity during incarceration (from $26.6 \%$ at admission to $45.4 \%$ at follow-up). This excessive weight gain is concerning and could lead to obesity-related health problems for these individuals.

Penitentiaries in Japan have been shown to be less obesogenic than the general community. Most Japanese inmates lost weight, and BMI scores decreased during incarceration.
Table 1: Sociodemographic factors for all participants

$\begin{array}{lc} & \text { No. (\%) } \\ \text { Factor } & n=1420\end{array}$

\section{Sex}

Male

1276 (89.9)

Female 144 (10.1)

Age, yr

18 to $\leq 24$ $104(7.3)$

$\geq 25$ to $\leq 34$ 389 (27.4)

$\geq 35$ to $\leq 44$

315 (22.2)

$\geq 45$ to $\leq 64$ 504 (35.5)

$\geq 65$

$108(7.6)$

Region

Atlantic

520 (36.6)

Ontario

900 (63.4)

First language

English

1265 (89.1)

French

155 (10.9)

Ethnicity

White

904 (63.7)

Black

203 (14.3)

Aboriginal

214 (15.1)

Other

99 (7.0)

Feeding system

Tray (menu)

393 (27.7)

Cafeteria (menu)

$522(36.8)$

Kitchenette (no menu)

505 (35.6)

Security level

Maximum

348 (24.5)

Medium

$781(55.0)$

Minimum

291 (20.5)

Length of incarceration at follow-up

$\leq 18 \mathrm{mo}$

553 (38.9)

$>18$ mo to $\leq 5 \mathrm{yr}$

458 (32.3)

$>5 \mathrm{yr}$

409 (28.8)

Length of sentence, $\mathrm{yr}$

2 to $\leq 3$

$285(20.1)$

$>3$ to $\leq 5$

$286(20.1)$

$>5$ to $\leq 25$

365 (25.7)

$>25$

$484(34.1)$

Unlike Canadian inmates, Japanese inmates follow strict lowcalorie diets and are obliged to work and exercise daily. ${ }^{18,19}$ However, Japanese inmates were the only outliers in a recent systematic review that examined weight changes during 
Research

\begin{tabular}{|c|c|c|c|c|}
\hline Category & $\mathrm{BMI}$ range & $\begin{array}{c}\text { Admission, no. (\%) } \\
n=1420\end{array}$ & $\begin{array}{c}\text { Follow-up, no. (\%) } \\
\qquad n=1420\end{array}$ & $p$ value \\
\hline Underweight & $<18.5$ & $17(1.2)$ & $\mathrm{F}$ & $<0.0001^{*}$ \\
\hline Normal & $18.5-24.9$ & $466(32.8)$ & $222(15.6)$ & \\
\hline Overweight & $25.0-29.9$ & $559(39.4)$ & $551(38.8)$ & \\
\hline Obese & $\geq 30.0$ & $378(26.6)$ & $645(45.4)$ & \\
\hline Overweight and obese & $\geq 25$ & $937(66.0)$ & $1196(84.2)$ & \\
\hline Obesity class I & $30.0-34.9$ & $236(16.6)$ & $405(28.5)$ & \\
\hline Obesity class II & $35.0-39.9$ & $92(6.5)$ & $146(10.3)$ & \\
\hline Extreme obesity class III & $\geq 40.0$ & $50(3.5)$ & $94(6.6)$ & \\
\hline
\end{tabular}

\begin{tabular}{|c|c|c|c|c|c|c|}
\hline Characteristic & $\begin{array}{l}\text { Median weight } \\
\text { change, kg } \\
(95 \% \mathrm{Cl})\end{array}$ & $p$ value* & $\begin{array}{l}\text { Median BMI change } \\
(95 \% \mathrm{Cl})\end{array}$ & $p$ value* & $\begin{array}{l}\text { Median annual rate of } \\
\text { change, } \mathrm{kg} / \mathrm{yr}(95 \% \mathrm{Cl})\end{array}$ & $p$ value* \\
\hline Overall & $+6.20(5.55-6.85)$ & & $+2.00(1.79-2.21)$ & & $+1.52(1.24-1.81)$ & \\
\hline \multicolumn{7}{|l|}{ Sex } \\
\hline Male & $+6.50(5.82-7.18)$ & \multirow[t]{2}{*}{0.3} & $+2.00(1.78-2.22)$ & \multirow[t]{2}{*}{0.7} & +1.46 (1.18-1.75) & \multirow[t]{2}{*}{0.2} \\
\hline Female & $+5.80(3.60-8.00)$ & & $+2.00(1.19-2.81)$ & & $+2.69(0.99-4.39)$ & \\
\hline \multicolumn{7}{|l|}{ Age, yr } \\
\hline 18 to $\leq 24$ & $+4.70(2.99-6.41)$ & \multirow[t]{5}{*}{0.05} & +1.60 (1.04-2.16) & \multirow[t]{5}{*}{0.04} & +3.51 (2.08-4.93) & \multirow[t]{5}{*}{$<0.0001$} \\
\hline$\geq 25$ to $\leq 34$ & $+5.70(4.62-6.78)$ & & $+1.80(1.45-2.15)$ & & $+2.30(1.63-2.98)$ & \\
\hline$\geq 35$ to $\leq 44$ & $+6.30(4.99-7.70)$ & & $+2.00(1.55-2.45)$ & & $+2.13(1.35-2.92)$ & \\
\hline$\geq 45$ to $\leq 64$ & $+7.60(6.35-8.85)$ & & $+2.50(2.09-2.91)$ & & +1.03 (0.68-1.39) & \\
\hline$\geq 65$ & $+5.30(3.87-9.46)$ & & $+1.75(1.28-3.10)$ & & $+0.51(0.16-0.85)$ & \\
\hline \multicolumn{7}{|l|}{ Region } \\
\hline Atlantic & $+5.05(4.00-6.10)$ & \multirow[t]{2}{*}{0.0004} & +1.70 (1.35-2.05) & \multirow[t]{2}{*}{0.002} & +1.42 (0.91-1.92) & \multirow[t]{2}{*}{0.1} \\
\hline Ontario & $+7.10(6.28-7.92)$ & & $+2.30(2.04-2.56)$ & & +1.57 (1.22-1.92) & \\
\hline \multicolumn{7}{|l|}{ First language } \\
\hline English & $+6.30(5.61-6.99)$ & \multirow[t]{2}{*}{0.3} & $+2.00(1.78-2.22)$ & \multirow[t]{2}{*}{0.4} & +1.50 (1.20-1.80) & \multirow[t]{2}{*}{0.9} \\
\hline French & $+6.00(4.08-7.92)$ & & $+1.90(1.28-2.52)$ & & $+1.75(0.78-2.72)$ & \\
\hline \multicolumn{7}{|l|}{ Ethnicity } \\
\hline White & $+6.30(5.47-7.13)$ & \multirow[t]{4}{*}{0.004} & $+2.00(1.73-2.27)$ & \multirow[t]{4}{*}{0.005} & $+1.42(1.07-1.78)$ & \multirow[t]{4}{*}{0.06} \\
\hline Black & $+7.00(5.54-8.46)$ & & $+2.20(1.75-2.65)$ & & $+2.06(1.22-2.90)$ & \\
\hline Aboriginal & $+7.70(6.92-10.52)$ & & $+2.40(1.83-2.97)$ & & $+1.72(0.89-2.54)$ & \\
\hline Other & +3.30 (1.61-4.99) & & $+1.00(0.77-1.86)$ & & $+1.14(0.49-1.78)$ & \\
\hline
\end{tabular}

incarceration. ${ }^{7}$ The findings from 16 different studies showed that $50 \%-80 \%$ of inmates gained weight during incarceration in the United States and United Kingdom. ${ }^{3,7,9,20-23}$ The amount and pace of weight gained varied by study, and ranged from a modest mean gain of $0.96 \mathrm{~kg}$ over 2 years $^{3}$ to a substantial $0.5-\mathrm{kg}$ gain per week. ${ }^{9}$ The latter study involved female 
Table 4: Median change in weight and body mass index, and annual rate of change, between admission and follow-up by institutional characteristic

\begin{tabular}{|c|c|c|c|c|c|c|}
\hline Characteristic & $\begin{array}{l}\text { Median weight } \\
\text { change in } \mathrm{kg} \\
(95 \% \mathrm{Cl})\end{array}$ & $p$ value* & $\begin{array}{l}\text { Median BMI change } \\
\qquad(95 \% \mathrm{Cl})\end{array}$ & $p$ value* & $\begin{array}{l}\text { Median annual } \\
\text { weight change } \\
\text { in kg/yr }(95 \% \mathrm{Cl})\end{array}$ & $p$ value* \\
\hline Overall & $+6.20(5.55-6.85)$ & & $+2.00(1.79-2.21)$ & & +1.52 (1.24-1.81) & \\
\hline \multicolumn{7}{|l|}{ Feeding system } \\
\hline Tray (menu) & $+6.00(4.83-7.17)$ & \multirow[t]{3}{*}{0.97} & +1.90 (1.52-2.28) & \multirow[t]{3}{*}{0.97} & +1.48 (0.98-1.97) & \multirow[t]{3}{*}{0.97} \\
\hline Cafeteria (menu) & +6.85 (5.75-7.95) & & $+2.20(1.86-2.54)$ & & +1.63 (1.18-2.08) & \\
\hline Kitchenette (no menu) & $+6.50(5.41-7.59)$ & & $+2.10(1.74-2.46)$ & & $+1.50(0.93-2.07)$ & \\
\hline \multicolumn{7}{|l|}{ Security level } \\
\hline Maximum & $+5.55(4.32-6.78)$ & \multirow[t]{3}{*}{0.05} & $+1.80(1.42-2.18)$ & \multirow[t]{3}{*}{0.04} & +1.45 (0.94-1.95) & \multirow[t]{3}{*}{0.1} \\
\hline Medium & $+7.00(6.10-7.90)$ & & $+2.30(2.01-2.59)$ & & $+1.79(1.39-2.19)$ & \\
\hline Minimum & $+5.55(4.07-6.93)$ & & $+1.80(1.34-2.26)$ & & +1.02 (0.24-1.81) & \\
\hline \multicolumn{7}{|c|}{ Length of incarceration at follow-up } \\
\hline$\leq 18 \mathrm{mo}$ & $+5.60(4.70-6.50)$ & \multirow[t]{3}{*}{0.001} & $+1.90(1.60-2.20)$ & \multirow[t]{3}{*}{0.001} & $+6.40(5.33-7.47)$ & \multirow[t]{3}{*}{$<0.001$} \\
\hline$>18 \mathrm{mo}$ to $\leq 5 \mathrm{yr}$ & $+5.75(4.65-6.85)$ & & $+1.80(1.45-2.15)$ & & $+2.09(1.67-2.51)$ & \\
\hline$>5 \mathrm{yr}$ & $+8.40(6.92-9.88)$ & & $+2.70(2.23-3.17)$ & & $+0.64(0.54-0.74)$ & \\
\hline \multicolumn{7}{|l|}{ Length of total sentence, $\mathrm{yr}$} \\
\hline 2 to $\leq 3$ & +6.00 (4.63-7.37) & \multirow[t]{4}{*}{0.006} & +2.00 (1.55-2.45) & \multirow[t]{4}{*}{0.007} & $+6.21(4.76-7.66)$ & \multirow[t]{4}{*}{$<0.001$} \\
\hline$>3$ to $\leq 5$ & $+6.25(4.99-7.51)$ & & $+2.00(1.60-2.40)$ & & $+3.74(2.78-4.70)$ & \\
\hline$>5$ to $\leq 25$ & $+5.50(4.35-6.65)$ & & +1.70 (1.33-2.07) & & +1.95 (1.44-2.46) & \\
\hline$>25$ & $+7.70(6.36-9.04)$ & & $+2.50(2.06-2.94)$ & & $+0.69(0.56-0.81)$ & \\
\hline
\end{tabular}

inmates in the US and was based on weight gained during the first 2 weeks of incarceration., ${ }^{7,9}$

Our findings suggest that weight gain was more rapid in the first months of incarceration. A median weight gain of $6.4 \mathrm{~kg} / \mathrm{yr}$ was noted among inmates incarcerated for less than 18 months, compared with $0.64 \mathrm{~kg} / \mathrm{yr}$ among inmates incarcerated for more than 5 years at the time of study. Rapid weight gain in the beginning of incarceration could be the result of withdrawal from alcohol, drugs and tobacco. ${ }^{9}$ It is well-established that inmates have higher rates of smoking and substance dependence than are seen in the general population. ${ }^{24,25}$ In support of this hypothesis, studies performed in penitentiaries where inmates were allowed to smoke tobacco reported modest weight gain. $2,3,23,26$ Tobacco withdrawal could explain the variation in gains between studies. In Canada, tobacco became prohibited in federal penitentiaries in 2008. ${ }^{27}$ This prohibition may contribute to weight gain for some inmates, because people who smoke tend to have lower BMIs than those who do not, ${ }^{28}$ and smoking cessation typically leads to weight gain. ${ }^{29}$

On admission to the penitentiary, inmates had rates of obesity similar to those of the general Canadian adult population ( $27 \%$ for both groups). However, during incarceration, the prevalence of obesity among inmates increased to $45.4 \%$. The proportion of inmates with weight in the normal range also changed during incarceration. On admission, $32.8 \%$ of inmates had a normal BMI; that proportion had decreased to $15.6 \%$ at follow-up. On admission, the proportion of inmates with a normal BMI $(32.8 \%)$ was similar to the proportion seen in the general Canadian adult population (36.1\%). ${ }^{6}$ Thus, there is little difference in proportions of people in each BMI category between inmates on admission to a penitentiary and the general population. However, during incarceration, the proportion of inmates in the normal and obese ranges changes substantially.

The rate at which Canadian inmates gain weight (median $1.5 \mathrm{~kg} / \mathrm{yr}$; mean $4.3 \mathrm{~kg} / \mathrm{yr}$ ) is higher than the rate of weight gain in nonincarcerated Canadian adults $(0.37 \mathrm{~kg} / \mathrm{yr}$ for men, 0.29 $\mathrm{kg} / \mathrm{yr}$ for women), and our findings suggest that inmates tend to gain more weight during the beginning of their incarceration. Thus, inmates gain excessive weight throughout their incarceration, but the rate at which they gain weight decreases over time. Moreover, only $45 \%$ of the Canadian adults gained weight in 2006, compared with $73 \%$ of inmates..$^{30}$ In the community, men tend to gain weight more rapidly than women. ${ }^{30}$ However, the opposite is seen in the correctional setting, where many studies have shown weight gain to be more severe for women than for men.,21,31 Because we did not see a significant difference between men and women in terms of weight outcomes in our study, we can conclude that sex did not influence weight gain, suggesting that Canadian correctional institutions are equally obesogenic for men and women. 
Some Canadian penitentiaries have a central feeding system that uses a standardized menu, ${ }^{32}$ whereas other institutions have a feeding system in which inmates purchase and prepare their own foods. ${ }^{15} \mathrm{We}$ found no significant difference in weight gain based on these different feeding systems.

\section{Limitations}

The observational nature of the data precludes inferences about causality. Residual confounding by unmeasured variables is always possible in observational studies. It was not possible to create a cohort of nonincarcerated adults to match our sample, which would have provided a better comparison group. We used the best data available from Statistics Canada, ${ }^{6}$ which allowed us to compare our results with the broader context of obesity in Canada.

\section{Conclusion}

Our study provides evidence that correctional institutions in Canada are obesogenic environments. Inmates come into prison with higher BMIs compared with the general adult population, and most inmates gain weight during incarceration. Prison could be an opportunity to address the health needs of inmates, many of whom come from marginalized or vulnerable populations. This opportunity may be missed if the environment is so obesogenic that the most important change to inmates' physical health status is weight gain. Releasing inmates in poorer health than when they were admitted into the penitentiaries is a likely scenario. Further research should identify strategies to make the correctional environment less obesogenic.

\section{References}

1. Obesity and overweight - fact sheet. Geneva: World Health Organization; 2016.

2. Herbert K, Plugge E, Foster C, et al. Prevalence of risk factors for noncommunicable diseases in prison populations worldwide: a systematic review. Lancet 2012;379:1975-82

3. Gates ML, Bradford RK. The impact of incarceration on obesity: Are prisoners with chronic diseases becoming overweight and obese during their confinement? F Obes 2015;2015:532468.

4. Health in prison: a WHO guide to the essentials in prison health. In: Moller L, Stover H, Jurgens R, et al., editors. Copenhagen: World Health Organization; 2007.

5. Stewart LA, Nolan A, Sapers J, et al. Chronic health conditions reported by male inmates newly admitted to Canadian federal penitentiaries. CMA7 Open 2015;3:E97-102.

6. Measured adult body mass index (BMI) (World Health Organization classification), by age group and sex, Canada and provinces, Canadian Community Health Survey nutrition [table 13-10-0794-01]. Ottawa: Statistics Canada; 2015.

7. Gebremariam MK, Nianogo RA, Arah OA. Weight gain during incarceration: systematic review and meta-analysis. Obes Rev 2018;19:98-110.

8. Reitano J. Adult correctional statistics in Canada, 2015/2016. Statistics Canada; 2017. Cat no 85-002-X

9. Clarke JG, Waring ME. Overweight, obesity, and weight change among incarcerated women. 7 Correct Health Care 2012;18:285-92.

10. Corrections and conditional release statistical overview. Ottawa: Public Safety Canada; 2017.

11. Canadian Public Health Association. A health care needs assessment of federal inmates in Canada. Can 7 Public Health 2004;95(Suppl 1):1-63.

12. Swinburn B, Egger G. Preventive strategies against weight gain and obesity. Obes Rev 2002;3:289-301.

13. Lake A, Townshend TG. Obesogenic environments: exploring the built and food environments. 7 R Soc Promot Health 2006;126:262-7.

14. Ball K, Crawford D, Timperio A, et al. Eating behaviors and the food environment. In: Lake A, Townshend TG, Alvanides S, editors. Obesogenic environments - complexities, perceptions and objective measures. Oxford (UK): Wiley-Blackwell; 2010:149-63.

15. Institutional profiles. Ottawa: Correctional Service Canada; 2013. Available: www.csc-scc.gc.ca/institutions/index-eng.shtml (accessed 2018 Jan. 31).

16. WHO Expert Committee. Physical status: the use and interpretation of anthropometry. Geneva: World Health Organization; 1995

17. Gostin LO, Vanchieri C, Pope A. Ethical considerations for research involving prisoners. Washington (DC): Institute of Medicine of the National Academies; 2007.

18. Hinata M, Ono M, Midorikawa S, et al. Metabolic improvement of male prisoners with type 2 diabetes in Fukushima Prison, Japan. Diabetes Res Clin Pract 2007;77:327-32.

19. Nara K, Igarashi M. Relationship of prison life style to blood pressure, serum lipids and obesity in women prisoners in Japan. Ind Health 1998;36:1-7.

20. Baldwin N, Clarke JG, Roberts MB. Weight change during incarceration: groundwork for a collaborative health intervention. 7 Health Care Poor Underserved 2016;27:1567-76.

21. Drach LL, Maher JE, Braun MJ, et al. Substance use, disordered eating, and weight gain: describing the prevention and treatment needs of incarcerated women. 7 Correct Health Care 2016;22:139-45.

22. Fogel CI. Hard time: the stressful nature of incarceration for women. Issues Ment Health Nurs 1993;14:367-77.

23. Plugge EH, Foster CE, Yudkin PL, et al. Cardiovascular disease risk factors and women prisoners in the UK: the impact of imprisonment. Health Promot Int 2009;24:334-43.

24. Bailey ZD, Okechukwu C, Kawachi I, et al. Incarceration and current tobacco smoking among Black and Caribbean Black Americans in the National Survey of American Life. Am 7 Public Health 2015;105:2275-82.

25. Standing Committee on Public Safety and National Security. Mental health and drug and alcohol addiction in the federal correctional system: report of the Standing Committee on Public Safety and National Security. 40th Parliament, 3rd session. Ottawa: House of Commons Canada; 2010.

26. Lagarrigue A, Ajana S, Capuron L, et al. Obesity in French inmates: gender differences and relationship with mood, eating behavior and physical activity. PLoS One 2017;12:e170412.

27. Collier R. Prison smoking bans: clearing the air. CMA7 2013;185:E474.

28. Obesity in Canada - a joint report from the Public Health Agency of Canada and the Canadian Institute for Health Information. Ottawa: Public Health Agency of Canada, Canadian Institute for Health Information; 2011.

29. Cropsey KL, McClure LA, Jackson DO, et al. The impact of quitting smoking on weight among women prisoners participating in a smoking cessation intervention. Am $\mathcal{F}$ Public Health 2010;100:1442-8.

30. Trends in weight change among Canadian adults: evidence from the 1996/1997 to 2004/2005 National Population Health Survey. In: Healthy today, bealthy tomorrow? Findings from the National Population Health Survey. Ottawa: Statistics Canada; [updated 2018]. Cat no 82-618-M.

31. Clarke JG, Waring ME. Overweight, obesity, and weight change among incarcerated women. 7 Correct Health Care 2012;18:285-92.

32. Harris K. $\$ 5.41$ per inmate per day: bad food, small portions fueling prison tensions. CBC News 2017 Oct. 31.

Affiliations: Interdisciplinary School of Health (Johnson), University of Ottawa; Healthy Active Living and Obesity Research Group (Chaput); Children's Hospital of Eastern Ontario Research Institute; School of Epidemiology and Public Health (Diasparra, Richard, Dubois), University of Ottawa, Ottawa, Ont.

Contributors: Claire Johnson and Lise Dubois directed data planning, data collection and data analysis for the study. Jean-Philippe Chaput provided guidance on which outcomes to examine and which statistical tests to perform. Maikol Diasparra performed all statistical analyses. Claire Johnson drafted the manuscript. Catherine Richard coded the data and prepared it for statistical analysis. All of the authors contributed to the conception and design of the study and the interpretation of the data, critically revised the manuscript for important intellectual content, gave final approval of the version to be published and agreed to be accountable for all aspects of the work.

Funding: This study was funded by the Consortium national de formation en santé (CNFS). The funders had no involvement in study design; collection, analysis or interpretation of data; writing the manuscript; or the decision to submit the manuscript for publication.

Supplemental information: For reviewer comments and the original submission of this manuscript, please see www.cmajopen.ca/content/6/3/ E347/suppl/DC1. 